\title{
STUDY OF MAZEF, SAM, AND PHD-DOC PUTATIVE TOXIN-ANTITOXIN SYSTEMS IN STAPHYLOCOCCUS EPIDERMIDIS
}

\author{
Sadeghi Kalani Behrooz ${ }^{1}$, Lotfollahi LidA ${ }^{2}$, Shivaee Ali ${ }^{1}$, \\ MOGHADAMPOUR MEHDI ${ }^{3}$, MirZAEI RASOUL ${ }^{1}$, OHADI ElNAZ ${ }^{1}$, \\ BIDEROUNI TAHVILDAR FARID ${ }^{4}$ and IRAJIAN GHOLAMREZA ${ }^{1} *$ \\ ${ }^{1}$ Department of Microbiology, School of Medicine, Iran University of Medical Sciences, \\ Tehran, Iran \\ ${ }^{2}$ Faculty of Medicine, Department of Microbiology, Urmia University of Medical \\ Sciences, Urmia, Iran \\ ${ }^{3}$ Department of Bacteriology and Virology, Isfahan University of Medical Sciences, \\ Isfahan, Iran \\ ${ }^{4}$ Faculty of medicine, Department of Parasitology and Mycology, Shahid Beheshti \\ University of Medical Sciences, Tehran, Iran
}

(Received: 20 July 2017; accepted: 21 November 2017)

Today, to replace the antibacterial targets to overcome antibiotic resistance, toxin-antitoxin (TA) system is noticeable, where the unstable antitoxin neutralizes the stable toxin and protects the bacteria against the toxic effects. The presence and expression of TA genes in clinical and non-clinical strains of Staphylococcus epidermidis were investigated in this study. After identification of three TA pairs (mazEF, sam, and phd-doc) via existing databases (earlier, there has been no information in the case of $S$. epidermidis isolates), the presence and expression of these pairs were investigated by PCR and q-PCR, respectively. We detected three TA modules in all antibiotic sensitive and resistant isolates. In addition, q-PCR analysis revealed that the transcripts were produced from the three TA modules. This study showed the significant prevalence of these systems in pathogenic bacteria and they were equally found in both oxacillin-resistant and oxacillin-susceptible bacteria. The high prevalence of three systems can make them suitable as potential targets for antibiotic therapy.

Keywords: $S$. epidermidis, toxin-antitoxin system, antibiotic resistance, real-time PCR

*Corresponding author; E-mail: dr.irajian@gmail.com 


\section{Introduction}

Toxin-antitoxin (TA) systems are small, bicistronic genetic elements that are found on plasmids or chromosomes of bacteria. These systems have two parts: a stable part called toxin protein that targets an essential cellular process and an unstable part called antitoxin that acts as a direct inhibitor or controls toxin production [1-4].

TA loci are often associated with pathogenic bacteria and most of them have been found on plasmids containing antibiotic resistance genes [5].

The first TA system was discovered in Escherichia coli. Over the years, TA systems have been identified in many bacteria. Nowadays, based on the mode of action and types of the antitoxin (can be a protein or RNA but toxins are always proteins), six different types of TA systems have been identified. In type I systems, the antitoxin suppresses the activity of the toxin protein by binding to mRNA toxin. In types II and III, protein antitoxins and the RNA antitoxin directly bind to the toxin proteins and block the activity of toxin proteins, respectively. In type IV, antitoxin protein prevents the activity of the toxin by binding to its substrate. Type $\mathrm{V}$, identified as an endoribonuclease, cuts the toxin mRNA specifically. Type VI, which is the last-type antitoxin molecules, acts as a proteolytic adapter, promoting the degradation of the toxin protein [2, 6-8]. Importantly, these systems have not only been reported to be associated with bacterial persistence but also have been reported to have roles in biofilm formation. These systems are proposed to be considered as novel bacterial targets for antimicrobial therapy in pathogenic bacteria [9].

One of the pathogenic bacteria that has a role in nosocomial infections is S. epidermidis. This bacterium, as a member of human skin flora [10], participates in wide spectrum of infections by residing in medical devices $[10,11]$. Unfortunately, in recent decades, antibiotic consumption in hospital wards and development of different resistance mechanisms in $S$. epidermidis have led to the situation of emergence as limited number of antibacterial agents (e.g., vancomycin and linezolid) are available for treatment in severe hospitalacquired infections [12].

If one of these TA systems is identified in all pathogenic clinical strains, the TA systems would be a good target for antibiotic therapy for pathogenic bacteria. For example, small molecules could be used to interrupt the TA system interaction that would free the toxin to kill the host cell [13-15].

Therefore, it is necessary to study the prevalence of TA systems and evaluate the TA systems as new targets in clinical pathogenic S. epidermidis. 


\section{Methods and Methods}

\section{Bacterial isolates and identification}

In total, $107 \mathrm{~S}$. epidermidis isolates obtained from clinical [including blood $(n=32)$, wound $(n=17)$, human flora $(n=28)$, and urine $(n=24)]$, and non-clinical samples [collected from laboratory environment $(n=6)$ ] (Table I) were collected during 5-month period from different hospitals and laboratories in Tehran, Iran. The strains were identified as $S$. epidermidis by standard laboratory tests, such as catalase, coagulase tests, resistance to polymyxin B and bacitracin disks, sensitivity to novobiocin disk, and mannitol fermentation test.

\section{Antimicrobial susceptibility testing}

Susceptibility to six antibacterial agents including vancomycin $(30 \mu \mathrm{g})$, cefoxitin $(30 \mu \mathrm{g})$ (as marker to detect of methicillin resistance or oxacillin resistance), linezolid $(30 \mu \mathrm{g})$, tetracycline $(30 \mu \mathrm{g})$, erythromycin $(15 \mu \mathrm{g})$, and clindamycin $(2 \mu \mathrm{g})$ was determined by disk diffusion method as CLSI guideline. Staphylococcus aureus strain ATCC 25923 used for quality control of disk diffusion method [16].

\section{Identification of TA genes in S. epidermidis}

To find TA genes in S. epidermidis, we obtained the complete genome of S. epidermidis ATCC 12228 and S. epidermidis isolate BPH0662 from NCBI and via different databases $[17,18]$ and we managed to find the common TA loci (type II) in these bacteria ( $m a z E F$, sam, and phd-doc) (Figure 1). Finally, specific primers were designed using oligo software version 7.56 (Table II) [19].

Table I. The source of $S$. epidermidis isolates

\begin{tabular}{lcc}
\hline $\begin{array}{l}\text { Sources of } \\
\text { isolates }\end{array}$ & \multicolumn{1}{c}{ Isolates } & $\begin{array}{c}\text { Number of } \\
\text { isolates }\end{array}$ \\
\hline Wound & $1-5,8,9,23,29-31,34,50,77,78,97,103$ & 17 \\
Blood & $6,10-12,20,22,27,28,38,39,46,48,49,52,55-57,61-63,67,68$, & 32 \\
& $76,79,98-100$ & 24 \\
Urine & $7,15-19,21,24,26,37,41,47,51,58-60,65,66,75,80,81,94,96$, & \\
& 95,102 & 28 \\
Flora & $14,101,32,33,40,42,44,53,54,64,69-75,82-90,92,93,43$ & 6 \\
Environment & $91,13,25,35,36,45$ & \\
\hline
\end{tabular}




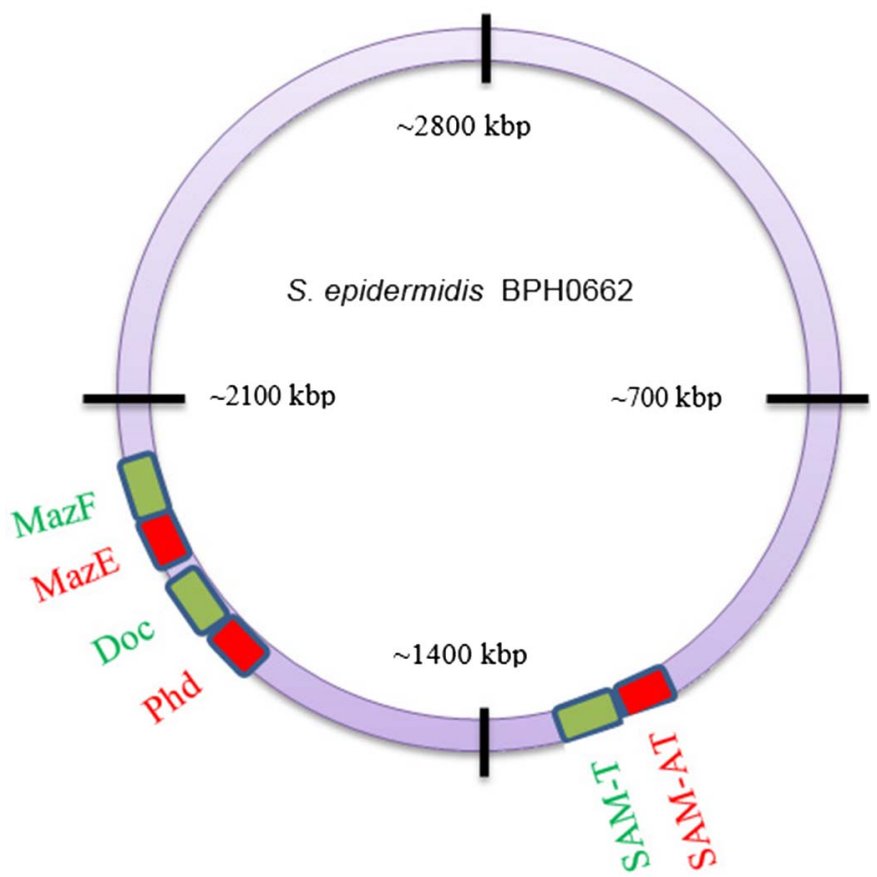

Figure 1. Genomic location of TA system in the chromosome of S. epidermidis isolate BPH0662

Table II. Characteristics of design primers and related genes used in the study

\begin{tabular}{|c|c|c|c|c|c|c|}
\hline $\begin{array}{l}\text { TA } \\
\text { system }\end{array}$ & & Sequence $\left(5^{\prime} \rightarrow 3^{\prime}\right)$ & TM & $\begin{array}{l}\text { Amplicon } \\
\text { (bp) }\end{array}$ & $\begin{array}{l}\text { Chromosome } \\
\text { location }^{\mathrm{a}}\end{array}$ & Reference \\
\hline$m a z F$ & $\begin{array}{l}\mathrm{F} \\
\mathrm{R}\end{array}$ & $\begin{array}{l}\text { CAAGGGGGAGTAAGACCTGT } \\
\text { TTAATCCTACCAGTAATCGCAGC }\end{array}$ & 58 & 95 & $\begin{array}{c}1934159- \\
1934521\end{array}$ & $\begin{array}{l}\text { This } \\
\text { study }\end{array}$ \\
\hline $\operatorname{maz} E$ & $\begin{array}{l}\mathrm{F} \\
\mathrm{R}\end{array}$ & $\begin{array}{l}\text { GAAGGTTATGCACAAATGGC } \\
\text { TTGCAATCACAAGCTTCACA }\end{array}$ & 56 & 83 & $\begin{array}{c}1934518- \\
1934688\end{array}$ & $\begin{array}{l}\text { This } \\
\text { study }\end{array}$ \\
\hline$d o c$ & $\begin{array}{l}\mathrm{F} \\
\mathrm{R}\end{array}$ & $\begin{array}{l}\text { GCTCAAAAGCACGCATTCCAT } \\
\text { ACCGCTTCATCTTGAGTGCAT }\end{array}$ & 60 & 110 & $\begin{array}{l}1807207- \\
1807602\end{array}$ & $\begin{array}{l}\text { This } \\
\text { study }\end{array}$ \\
\hline phd & $\begin{array}{l}\mathrm{F} \\
\mathrm{R}\end{array}$ & $\begin{array}{l}\text { GCACTCGGAATATCAAATGGTG } \\
\text { AAACTCCTCGTCCTCTCTTAC }\end{array}$ & 57 & 93 & $\begin{array}{c}1807602- \\
1807769\end{array}$ & $\begin{array}{l}\text { This } \\
\text { study }\end{array}$ \\
\hline sam- $\mathrm{T}$ & $\begin{array}{l}\mathrm{F} \\
\mathrm{R}\end{array}$ & $\begin{array}{l}\text { TTGCTCGTTGATGGAATGGCTT } \\
\text { GCCCCATATCCCAACAAACTGC }\end{array}$ & 61 & 181 & $\begin{array}{c}1226550- \\
1227428\end{array}$ & $\begin{array}{l}\text { This } \\
\text { study }\end{array}$ \\
\hline sam-AT & $\begin{array}{l}\mathrm{F} \\
\mathrm{R}\end{array}$ & $\begin{array}{l}\text { GAAGTCAGCGCAGAAGCACAAT } \\
\text { AGTGGTCGCCTCATTAAGTCGT }\end{array}$ & 61 & 231 & $\begin{array}{c}1227447- \\
1230884\end{array}$ & $\begin{array}{l}\text { This } \\
\text { study }\end{array}$ \\
\hline
\end{tabular}

Note: ${ }^{\mathrm{a} O n}$ S. epidermidis isolate BPH0662. 
Detection of TA genes in S. epidermidis isolates

PCR assay was used to depict the presence of TA modules in the S. epidermidis isolates. PCR was performed in a DNA thermal cycler (Bio-Rad, USA) in a volume of $25 \mu \mathrm{l}$. The program consisted of an initial denaturation step at $94{ }^{\circ} \mathrm{C}$ for $4 \mathrm{~min}, 35 \times$ $94{ }^{\circ} \mathrm{C}$ for $30 \mathrm{~s}$, annealing (annealing Tm for each primer is indicated in Table II) for $30 \mathrm{~s}$, and extension at $72{ }^{\circ} \mathrm{C}$ for $20 \mathrm{~s}$. No template control was used as negative control. Finally, PCR products were sequenced (Macrogen, South Korea).

\section{Quantitative real-time polymerase chain reaction}

Bacteria were pelleted by centrifugation at 2,500 $\times g$ for $15 \mathrm{~min}$. Total RNA was isolated using the QIAGEN RNeasy Mini kit. Extracted RNA was analyzed using a nanodrop ND1000 and running on a denaturing 1.5\% Tris-acetate-EDTAagarose gels $(80 \mathrm{~V}$ for $1 \mathrm{~h})$ to assess RNA concentration, quality, and integrity. The RNA was DNase treated with Promega RNase-free DNase (at $37^{\circ} \mathrm{C}$ for $1 \mathrm{~h}$ ). RNA was precipitated with 1 volume isopropanol and 0.1 volume of $3 \mathrm{M} \mathrm{NaOAc}$ (pH 4.6). The suspension was incubated on ice for $20 \mathrm{~min}$ and centrifuged at high speed for $30 \mathrm{~min}$ at $4{ }^{\circ} \mathrm{C}$. The RNA was pellet, dried, and resuspended with RNase-free MilliQ $\mathrm{H}_{2} \mathrm{O}$. According to the manufacturer's instructions, $500 \mathrm{ng}-$ $1 \mu \mathrm{g}$ RNA was converted into cDNA using AccuPower CycleScript RT PreMix (Bioneer, Korea). Quantitative real-time PCR was performed in a Rotor-Gene thermal cycler (Corbett 6000, Australia) using SYBR Green method (AccuPower Green Star qPCR Master Mix, Bioneer, Korea). A total volume of $20 \mu 1$ reaction containing $2 \mu \mathrm{l}$ of cDNA, $12.5 \mu \mathrm{l} \mathrm{SYBR}$ Green master mix, $4.5 \mu 1$ nuclease-free water, and $1 \mu \mathrm{l}$ of each primer ( $5 \mathrm{pmol})$ was run according to following program: an initial activation step at $94{ }^{\circ} \mathrm{C}$ for $4 \mathrm{~min}, 35$ cycles of denaturation at $94{ }^{\circ} \mathrm{C}$ for $30 \mathrm{~s}$, annealing at (indicated in Table II) for $30 \mathrm{~s}$, and extension at $72{ }^{\circ} \mathrm{C}$ for $20 \mathrm{~s}$.

\section{Statistical analysis}

We used SPSS version 16 and chi-square program to assess the correlation between the presence of TA genes and antibiotic-resistance pattern in S. epidermidis isolates. A $P_{\text {value }} \leq 0.05$ was considered as significant.

\section{Results}

The antibiotic susceptibility pattern in all 107 S. epidermidis isolates showed $39.2 \%, 60.8 \%, 32 \%, 70.1 \%, 1 \%$, and $1 \%$ resistance to clindamycin, methicillin, 
tetracycline, erythromycin, linezolid, and vancomycin, respectively. The highest levels of resistance were seen to erythromycin and oxacillin, $70.1 \%(n=68)$ and $60.8 \%(n=59)$, respectively. The highest and lowest resistance to methicillin were observed in blood (79.3\%), environmental (77.8\%), urine (72\%), wound (60\%), and human flora isolates (20.8\%).

Surprisingly, urine, blood, and environmental isolates also had the highest resistance to erythromycin $(84 \%, 79.3 \%$, and $77.8 \%$, respectively) and the highest sensitivity was seen in human flora isolates $(58.3 \%)$.

Fortunately, all isolates were sensitive to linezolid and vancomycin except one vancomycin-resistant blood isolate and one linezolid-resistant environmental isolate.

The highest resistance to tetracycline and clindamycin was shown in wound isolates, whereas the highest sensitivity was seen in human flora isolates (in both antibiotics) and blood isolates (on the subject of tetracycline).

An attractive observation was the prevalence of three TA genes in these isolates (Figure 2). Notably, mazEF, sam, and phd-doc loci were presented in all $107 \mathrm{~S}$. epidermidis isolates. These results demonstrated that there is no difference between clinical and non-clinical and also resistant and sensitive isolates to antibiotics in presence of TA genes. Given to qPCR results, it could be concluded that the identified genes are transcriptionally activated and might be translated to the proteins or functionally active RNAs in the different strains of S. epidermidis.

\section{Discussion}

Nowadays, the consumption of common antibiotics in treatment of $S$. epidermidis infections has enhanced emergence of resistant isolates and has increased use of glycopeptide antibiotics (vancomycin). The high rate of resistance to methicillin (60.8\%) was despairing, but the sensitivity of majority of the isolates (99\%) to vancomycin and linezolid is promising. Therefore, vancomycin can be the best choice for S. epidermidis infections. Since, the rate of resistance to vancomycin is increasing, to meet this problem (one blood isolate in this study) and to find the new antibacterial targets that can be useful in treatment. TA system can be introduced as an antibacterial target [20]. The distribution of TA loci in different species is shown according to the analyses in databases and studies of prokaryotic genome [20].

However, there have been few studies about the existence and performance of TA loci in different bacterial species. Current studies on TA systems showed the possible roles of this system in antibiotic tolerance, biofilm formation, niche colonization, persistence, cell programmed death, chronic infections, and pathogenicity [21-26]. 


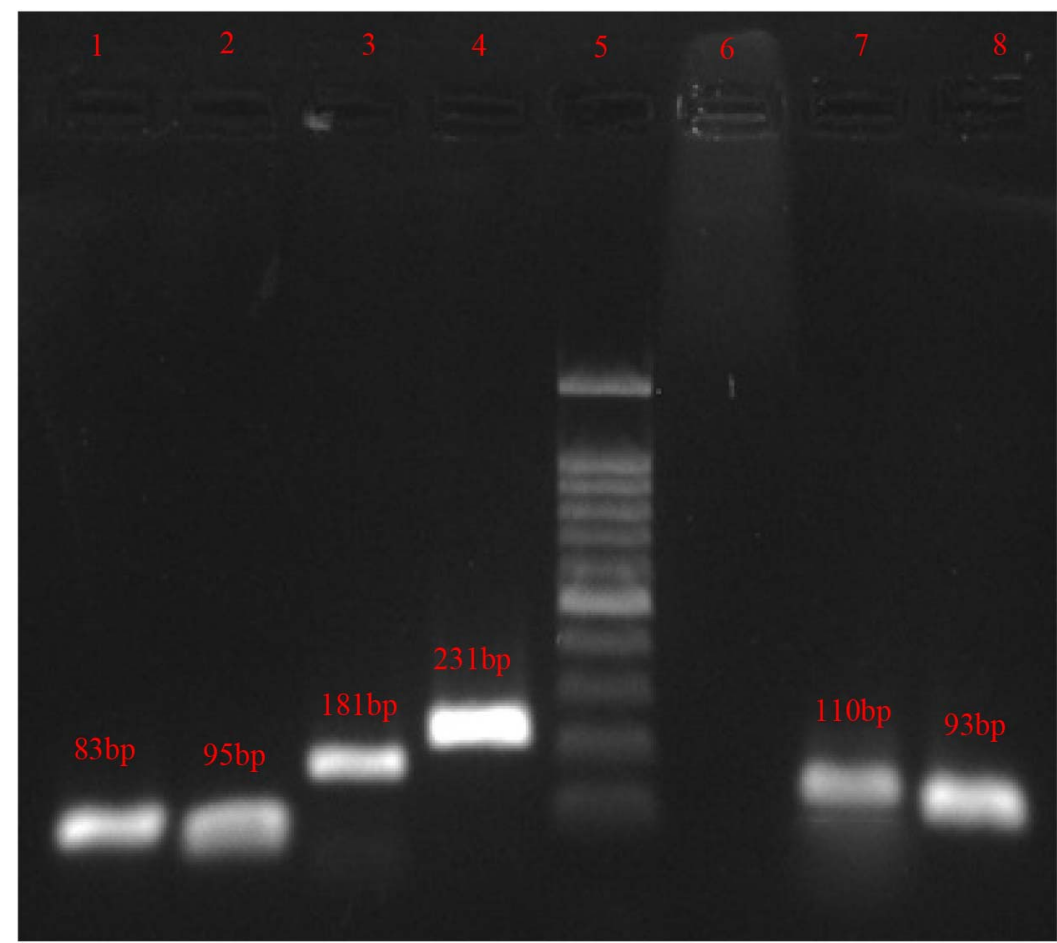

Figure 2. PCR detection of TA genes. Lane1, mazE; lane2, mazF; lane3, $\operatorname{sam} \mathrm{T}$; lane4, $\operatorname{samAT}$; lane5, ladder; lane6, negative control; lane7, doc; lane8, phd. (T: toxin, AT: antitoxin)

$S$. epidermidis is one of the common biofilm-producing bacteria and the cause of related infections [27]. Therefore, it is important to study factors involved in biofilm formation and increased tolerance to antibiotics in this bacteria as an important pathogen. As different types of TA systems have roles in biofilm formation, pathogenesis, and tolerance to antibiotics, and there have been no studies or analyses on these bacteria, it is important to study the prevalence and existence of these systems in this pathogenic bacteria.

Type II system is the most common among TA systems according to previous studies [28].

MazEF is one of the major groups of type II systems, which today is considered as one of the important TA systems in biofilm formation and tolerance to antibiotics [29]. PCR and qPCR used in this study showed that the prevalence of these systems in pathogenic bacteria is significant and found in both oxacillin-resistant and oxacillin-sensitive bacteria equally. The results showed that all the oxacillin-resistant and oxacillin-sensitive bacteria in this 
study had maz TA system with the prevalence of $100 \%$. A similar prevalence of this TA system was reported by Jain et al. [29]. They studied 101 MRSA strains and reported that $100 \%$ of biofilm-forming MRSAs had mazEF gene. Their study shows the same prevalence of this TA system as this study. Another study was conducted on the plasmid of 75 vancomycin-resistant enterococci (VRE) samples by Moritz and Hergenrother [30] and same results were reported. They showed in a study that all the plasmids had maz TA system. Maz system was mostly on the plasmid containing vanA gene. With the results of their study and high prevalence of mazEF in VRE plasmid, mazEF is expected to be found on plasmids of similar species, such as staphylococci and streptococci.

Phd-doc is another important type II TA system. This system is derived from P1 bacteriophage and is involved in stress responses, plasmid stability resistance, and essential performances, such as pathogenicity $[31,32]$. The results of this study, using PCR and real-time PCR, were the same as the results of maz TA and all the $S$. epidermidis strains resistant and sensitive to oxacillin had this system and also same prevalence of this system was observed in oxacillin-resistant and oxacillin-sensitive strains.

It is also noteworthy that there are no evidences about sam gene in other bacteria so far.

As this bacterium is known as a problem in hospitals for its ability to form biofilms and high prevalence and antibiotic resistance, finding new approaches to fight against pathogens is considered a worldwide priority in healthcare system. Therefore, if one of these TA systems is found in all clinical species, it could be a suitable target for antibiotic therapy.

In this study, which was based on PCR and qPCR techniques, all three TA systems including $m a z E F$, sam, and phd-doc were found in all 107 S. epidermidis isolates. The high prevalence of these three systems can make them suitable targets for antibiotic therapy.

\section{Acknowledgements}

All authors appreciated Department of Microbiology, Iran University of Medical Sciences. IG designed, drafted, analyzed, and supervised this study.

\section{Funding Sources}

This study was supported by Iran University of Medical Sciences, Tehran, IR Iran. 


\section{Conflict of Interest}

None.

\section{References}

1. Yamaguchi, Y., Park, J.-H., Inouye, M.: Toxin-antitoxin systems in bacteria and archaea. Annu Rev Genet 45, 61-79 (2011).

2. Ghafourian, S., Raftari, M., Sadeghifard, N., Sekawi, Z.: Toxin-antitoxin systems: Classification, biological function and application in biotechnology. Curr Issues Mol Biol 16, 9-14 (2013).

3. Sadeghifard, N., Soheili, S., Sekawi, Z., Ghafourian, S.: Is the mazEF toxin-antitoxin system responsible for vancomycin resistance in clinical isolates of Enterococcus faecalis? GMS Hyg Infect Control 9, (2014).

4. Savari, M., Rostami, S., Ekrami, A., Bahador, A.: Characterization of toxin-antitoxin (TA) systems in Pseudomonas aeruginosa clinical isolates in Iran. Jundishapur J Microbiol 9, e26627 (2016).

5. Mine, N., Guglielmini, J., Wilbaux, M., Van Melderen, L.: The decay of the chromosomally encoded $c c d_{O 157}$ toxin-antitoxin system in the Escherichia coli species. Genetics 181, 1557-1566 (2009).

6. Schuster, C. F., Bertram, R.: Toxin-antitoxin systems are ubiquitous and versatile modulators of prokaryotic cell fate. FEMS Microbiol Lett 340, 73-85 (2013).

7. Wang, X., Lord, D. M., Cheng, H.-Y., Osbourne, D. O., Hong, S. H., Sanchez-Torres, V., Quiroga, C., Zheng, K., Herrmann, T., Peti, W.: A new type V toxin-antitoxin system where mRNA for toxin GhoT is cleaved by antitoxin GhoS. Nat Chem Biol 8, 855-861 (2012).

8. Hall, A. M., Gollan, B., Helaine, S.: Toxin-antitoxin systems: Reversible toxicity. Curr Opin Microbiol 36, 102-110 (2017).

9. Mutschler, H., Meinhart, A.: $\varepsilon / \zeta$ systems: Their role in resistance, virulence, and their potential for antibiotic development. J Mol Med 89, 1183-1194 (2011).

10. Chaudhry, V., Patil, P. B.: Genomic investigation reveals evolution and lifestyle adaptation of endophytic Staphylococcus epidermidis. Sci Rep 6, 19263 (2016).

11. Vandecandelaere, I., Coenye, T.: Microbial composition and antibiotic resistance of biofilms recovered from endotracheal tubes of mechanically ventilated patients. In Gianfranco, D. (ed): Biofilm-Based Healthcare-Associated Infections. Springer, Cham, Switzerland, 2015, pp. 137-155.

12. Morgenstern, M., Erichsen, C., Hackl, S., Mily, J., Militz, M., Friederichs, J., Hungerer, S., Bühren, V., Moriarty, T. F., Post, V.: Antibiotic resistance of commensal Staphylococcus aureus and coagulase-negative staphylococci in an international cohort of surgeons: A prospective point-prevalence study. PLoS One 11, e0148437 (2016).

13. Engelberg-Kulka, H., Sat, B., Reches, M., Amitai, S., Hazan, R.: Bacterial programmed cell death systems as targets for antibiotics. Trends Microbiol 12, 66-71 (2004).

14. Gerdes, K., Christensen, S. K., Løbner-Olesen, A.: Prokaryotic toxin-antitoxin stress response loci. Nat Rev Microbiol 3, 371 (2005). 
15. DeNap, J. C., Hergenrother, P. J.: Bacterial death comes full circle: Targeting plasmid replication in drug-resistant bacteria. Org Biomol Chem 3, 959-966 (2005).

16. Drew, W. L., Barry, A., O'Toole, R., Sherris, J. C.: Reliability of the Kirby-Bauer disc diffusion method for detecting methicillin-resistant strains of Staphylococcus aureus. Appl Microbiol 24, 240-247 (1972).

17. Sevin, E. W., Barloy-Hubler, F.: RASTA-Bacteria: A web-based tool for identifying toxin-antitoxin loci in prokaryotes. Genome Biol 8, 1 (2007).

18. Shao, Y., Harrison, E. M., Bi, D., Tai, C., He, X., Ou, H.-Y., Rajakumar, K., Deng, Z.: TADB: A web-based resource for Type 2 toxin-antitoxin loci in bacteria and archaea. Nucleic Acids Res 39, D606-D611 (2011).

19. Rychlik, W.: OLIGO 7 Primer Analysis Software. In Yuryev, A. (ed): PCR Primer Design. Methods in Molecular Biology ${ }^{\mathrm{TM}}$. Humana Press, Totowa, NJ, 2007, Vol. 402.

20. Makarova, K. S., Wolf, Y. I., Koonin, E. V.: Comprehensive comparative-genomic analysis of type 2 toxin-antitoxin systems and related mobile stress response systems in prokaryotes. Biol Direct 4, 19 (2009).

21. Kim, Y., Wang, X., Ma, Q., Zhang, X.-S., Wood, T. K.: Toxin-antitoxin systems in Escherichia coli influence biofilm formation through YjgK (TabA) and fimbriae. J Bacteriol 191, 1258-1267 (2009).

22. Fineran, P. C., Blower, T. R., Foulds, I. J., Humphreys, D. P., Lilley, K. S., Salmond, G. P.: The phage abortive infection system, ToxIN, functions as a protein-RNA toxin-antitoxin pair. Proc Natl Acad Sci U S A, 106, 894-899 (2009).

23. Hazan, R., Engelberg-Kulka, H.: Escherichia coli mazEF-mediated cell death as a defense mechanism that inhibits the spread of phage P1. Mol Genet Genomics 272, 227-234 (2004).

24. Norton, J. P., Mulvey, M. A.: Toxin-antitoxin systems are important for niche-specific colonization and stress resistance of uropathogenic Escherichia coli. PLoS Pathog 8, e1002954 (2012).

25. Ren, D., Walker, A. N., Daines, D. A.: Toxin-antitoxin loci vapBC-1 and vapXD contribute to survival and virulence in nontypeable Haemophilus influenzae. BMC Microbiol 12, 263 (2012).

26. Rowe-Magnus, D. A., Guerout, A.-M., Biskri, L., Bouige, P., Mazel, D.: Comparative analysis of superintegrons: Engineering extensive genetic diversity in the Vibrionaceae. Genome Res 13, 428-442 (2003).

27. Namvar, A. E., Bastarahang, S., Abbasi, N., Ghehi, G. S., Farhadbakhtiarian, S., Arezi, P., Hosseini, M., Baravati, S. Z., Jokar, Z., Chermahin, S. G.: Clinical characteristics of Staphylococcus epidermidis: A systematic review. GMS Hyg Infect Control 9, (2014).

28. Yamaguchi, Y., Inouye, M.: Toxin-antitoxin systems in bacteria and archaea. In de Bruijn, Frans J. (ed): Stress and Environmental Regulation of Gene Expression and Adaptation in Bacteria. John Wiley \& Sons Inc., Hoboken, NJ, 2016, pp. 97-107.

29. Jain, S., SenGupta, M., Sinha, A., Sarkar, S.: Identification of MazEF toxin-antitoxin system and biofilm formation in clinical isolates of MRSA isolated from Eastern India. Al Ameen J Med Sci 9, 53-57 (2016). 
30. Moritz, E. M., Hergenrother, P. J.: Toxin-antitoxin systems are ubiquitous and plasmidencoded in vancomycin-resistant enterococci. Proc Natl Acad Sci U S A 104, 311-316 (2007).

31. Lehnherr, H., Maguin, E., Jafri, S., Yarmolinsky, M. B.: Plasmid addiction genes of bacteriophage P1: Doc, which causes cell death on curing of prophage, and phd, which prevents host death when prophage is retained. J Mol Biol 233, 414-428 (1993).

32. Garcia-Pino, A., Christensen-Dalsgaard, M., Wyns, L., Yarmolinsky, M., Magnuson, R. D., Gerdes, K., Loris, R.: Doc of prophage P1 is inhibited by its antitoxin partner Phd through fold complementation. J Biol Chem 283, 30821-30827 (2008). 